\title{
Linkage disequilibrium and haplotype block structure in a composite beef cattle breed
}

\author{
Fabiana Barichello Mokry ${ }^{1}$, Marcos Eli Buzanskas ${ }^{2}$, Maurício de Alvarenga Mudadu, Daniela do Amaral Grossi ${ }^{4}$, \\ Roberto Hiroshi Higa ${ }^{5}$, Ricardo Vieira Ventura ${ }^{4}$, Andressa Oliveira de Lima', Mehdi Sargolzaei ${ }^{4}$, \\ Sarah Laguna Conceição Meirelles ${ }^{6}$, Flávio Schramm Schenkel ${ }^{4}$, Marcos Vinicius Gualberto Barbosa da Silva ${ }^{7}$, \\ Simone Cristina Méo Niciura ${ }^{3}$, Maurício Mello de Alencar ${ }^{3}$, Danísio Prado Munari², \\ Luciana Correia de Almeida Regitano ${ }^{3^{*}}$
}

From 9th International Conference of the Brazilian Association for Bioinformatics and Computational Biology (X-Meeting 2013)

Recife, Brazil. 3-6 November 2013

\begin{abstract}
Background: The development of linkage disequilibrium (LD) maps and the characterization of haplotype block structure at the population level are useful parameters for guiding genome wide association (GWA) studies, and for understanding the nature of non-linear association between phenotypes and genes. The elucidation of haplotype block structure can reduce the information of several single nucleotide polymorphisms (SNP) into the information of a haplotype block, reducing the number of SNPs in a coherent way for consideration in GWA and genomic selection studies.
\end{abstract}

Results: The maximum average LD, measured by $\mathrm{r}^{2}$ varied between 0.33 to 0.40 at a distance of $<2.5 \mathrm{~kb}$, and the minimum average values of $r^{2}$ varied between 0.05 to 0.07 at distances ranging from 400 to $500 \mathrm{~kb}$, clearly showing that the average $r^{2}$ reduced with the increase in SNP pair distances. The persistence of LD phase showed higher values at shorter genomic distances, decreasing with the increase in physical distance, varying from 0.96 at a distance of $<2.5 \mathrm{~kb}$ to 0.66 at a distance from 400 to $500 \mathrm{~kb}$. A total of $78 \%$ of all SNPs were clustered into haplotype blocks, covering 1,57 Mb of the total autosomal genome size.

Conclusions: This study presented the first high density linkage disequilibrium map and haplotype block structure for a composite beef cattle population, and indicates that the high density SNP panel over $700 \mathrm{k}$ can be used for genomic selection implementation and GWA studies for Canchim beef cattle.

\section{Background}

With the advance in high-throughput single nucleotide polymorphism (SNP) detection and genotyping technologies, genome-wide association (GWA) and genomic selection (GS) studies in livestock have become of great interest. Nonetheless, both types of studies rely on the extent of linkage disequilibrium between markers across the genome. Linkage disequilibrium (LD) can be defined

\footnotetext{
*Correspondence: luciana.regitano@embrapa.br

${ }^{3}$ Embrapa Southeast Livestock, Rodovia Washington Luiz, km 234, PO BOX 339, 13560-970, São Carlos, Brazil

Full list of author information is available at the end of the article
}

as the non-random relationship of alleles between two loci within a population. The development of LD maps and the characterization of haplotype block structure at the population level are useful parameters for guiding GWA, candidate gene and candidate region studies [1], as well as for understanding the nature of non-linear association between phenotypes and genes. LD in a population can be affected by some factors, such as population structure, migration, selection, genetic drift, mutations and recombination rates [2].

A variety of studies can be found regarding linkage disequilibrium in cattle populations. The first genome-wide 
LD study was conducted in a Dutch black-and-white dairy cattle population based on 284 microsatellite markers [3]. From there on, many other studies have been performed and confirmed extensive LD in cattle [4-8], being followed by a second generation of LD maps developed with $30 \mathrm{k}$ or more SNPs spanning the entire bovine genome [9-12]. Lastly, a recent high density LD study on Nellore using $700 \mathrm{k}$ SNPs has been published [13], which can be considered the third generation of LD maps, concluding that the estimated LD for SNPs within a physical genomic distance of $30 \mathrm{~kb}$ corroborates the use of the $700 \mathrm{k}$ SNPs panel for genomic selection implementation in Nellore cattle.

Haplotype block studies are not as common as LD map studies in cattle. The elucidation of haplotype block structure can bring important considerations for GWA and GS studies, such as the possibility of selecting a set of SNPs with the prospect of reducing the information of several SNPs into the information of a haplotype block, reducing the number of SNPs in a coherent way [14], and optimizing the design and analysis of GWA. Haplotype blocks can also be used for detection of genomic regions under selection during evolution, and identification of signatures of recent positive selection [15].

With the new releases of commercial high density SNP panels with over $700 \mathrm{k}$ SNPs, it is possible to build high definition LD maps and haplotype blocks. In this study, we used the Illumina BovineHD BeadChip to investigate LD and persistence of LD phase patterns, as well as the haplotype block structure for Canchim, a composite breed of beef cattle. Canchim was originated in the early 1960's in Brazil from crosses between Bos primigenius indicus (zebu) and Bos primigenius taurus (Charolais) animals [16]. The final composition of Canchim animals is $5 / 8$ parts Charolais and 3/8 parts zebu (currently, the Nellore breed is the most common zebu breed used in the crosses to obtain Canchim animals). However, the Canchim Breeding Association allows for four different crossing schemes to generate Canchim animals, and one of these schemes, called UEPAE (Unidade de Execução de Pesquisa de Âmbito Estadual), produces animals with, on average, $3.1 \%$ more Charolais in the final composition, called MA animals, but they are still evaluated with other Canchim animals taking into account the differences in the percentage of each original breed (zebu and Charolais) [17].

\section{Methods}

\section{Animals}

In respect to the Canchim composition particularity, a sample of 399 animals (285 Canchim, 114 MA) was selected, and Canchim animals will be referred to as CA, the MA animals as MA, and the joint group of Canchim and MA animals as CAN. These 399 animals belong to seven herds located in two Brazilian states (São Paulo and
Goiás), and are registered in the Canchim Breeding Association database. This study has been performed with the approval of the Embrapa Southeast Livestock Ethical Committee of Animal Use (CEUA-CPPSE) under protocol number 02/2009.

The Canchim population is considered to be rather small, especially when compared to other breeds in Brazil. The herd is estimated to contain approximately 30,000 animals, according to data from the Canchim Breeding Association [18], and supplied just $0.12 \%$ of all beef cattle semen sales in Brazil [19]. However, this data set originated from 50 different bulls, comprised of Canchim and MA animals from the breed developer farm and other farms. This is representative of $0.01 \%$ of the entire Canchim population. For these reasons, we ignored the probable founder effects, and considered this sample to be representative of the current Canchim population.

\section{Genotyping and SNP quality control}

The 399 animals described above were genotyped using the BovineHD BeadChip (Illumina Inc., San Diego, CA), which consists of 786,799 SNPs evenly distributed along the bovine genome with an average distance of $3 \mathrm{~kb}$. In this study, sex chromosomes and loci without an assigned position in the Cattle Genome Assembly UMD 3.1 [20] were discarded, as well as animals with a call rate $<0.90$. The SNP quality control was carried out according to low call rates $(<0.90)$, Hardy-Weinberg equilibrium $(<0.0001)$, and minor allele frequency $(\mathrm{MAF})<0.05$, as extreme values of MAF can reduce the power to properly estimate linkage disequilibrium and persistence of LD phase [21].

\section{Linkage disequilibrium and persistence of linkage disequilibrium phase}

The data set was divided into Canchim and MA animals for an exploratory analysis of persistence of LD phase between both genetic groups, and LD estimation was performed using the SNPPLD tool available in the gebv software [22]. The LD measurement adopted in this study was $r^{2}$ [23], which is the correlation coefficient between SNP pairs, and was calculated according to the following equation:

$$
r_{i j}^{2}=\frac{p_{i j}-p_{i} \times p_{j}^{2}}{p_{i}\left(1-p_{i}\right) \times p_{j}\left(1-p_{j}\right)}
$$

where $p_{i j}$ is the frequency of the two-marker haplotype, and $p_{i}$, and $p_{j}$ are the marginal allelic frequencies in the $i^{\text {th }}$ and $j^{\text {th }}$ SNP, respectively [24]. The value of $\mathrm{r}^{2}$ can vary from 0 to 1 , where zero means no correlation between SNP pairs, and 1 means perfect correlation between the SNP pairs. Due to the significant amount of possible SNP pair-wise comparisons, the $\mathrm{r}^{2}$ calculation was limited to SNPs within maximum distances of $500 \mathrm{~kb}$ from each 
other, since $\mathrm{r}^{2}$-values obtained using SNPs with distances over $500 \mathrm{~kb}$ presented low LD values (data not shown), and to estimate all SNPs pair-wise comparisons would exponentially increase computing processing. Paternal and maternal haplotypes were utilized for the estimation of LD.

The persistence of LD phase was evaluated across genetic groups (CA and MA) by the Pearson correlation of the square root of $\mathrm{r}^{2}(r)$, by attributing the appropriate sign based on the calculated $\mathrm{D}$ value, called signed $r$. Persistence of LD phase calculation was performed according to the following equation:

$$
D=p_{i j}-\left(p_{i} \times p_{j}\right)
$$

where $p_{i j}, p_{i}$, and $p_{j}$ were defined as stated above. The results were ordered by chromosome (chr) and distance between SNPs.

\section{Haplotype block structure}

Haplotype block refers to a combination of alleles linked along a chromosome, which are inherited together from a common ancestor [25]. The haplotype block structure study was carried out using the joint CAN group. For doing this, the same quality control filters were applied through the PLINK v1.07 software [26], and the phase and haplotype reconstruction were performed using the BEAGLE Version 3.3.1 software [27] for each chromosome. Afterwards, the Haploview [28] software, which uses haplotype block definition by Gabriel et al. [29] by default, was used for estimating haplotype block patterns for the 29 pairs of autosome chromosomes, within SNPs at a maximum distance of $500 \mathrm{~kb}$.

\section{Results}

A total of 395 animals (283 CA and $112 \mathrm{MA}$ ) passed the quality control filters from the SNPPLD software, yielding a total of 716,089 SNPs for CA, 658,132 SNPs for MA, and 713,615 SNPs for CAN animals. The number of SNP pairs showed small variation among CA, MA, and CAN due to the quality control filtering, in which some SNPs were included for CA, MA, and CAN, and some other SNPs were not included, as shown in Table 1. The maximum average $\mathrm{r}^{2}$ of 0.40 was obtained for CA animals at a distance of $<2.5 \mathrm{~kb}$, while MA animals obtained an average $r^{2}$ of 0.33 , and the joint population (CAN) resulted in an average $r^{2}$ of 0.38 (Table 1 ). The average minimum values of $\mathrm{r}^{2}$ (0.07 CA, 0.05 MA, and $\left.0.06 \mathrm{CAN}\right)$ were obtained at a distance from 400 to $500 \mathrm{~kb}$ (Table 1), clearly showing that the average $r^{2}$ reduced with the increase in SNP pair distances. The average $r^{2}$, up to the physical genomic distance of $500 \mathrm{~kb}$, was slightly higher for CA animals, followed by CAN, and lastly, by MA animals (Figure 1). The persistence of LD phase between CA and MA animals showed higher values at shorter genomic distances, decreasing with the increase in physical distance (Figure 1). The persistence of LD phase varied from 0.96 at distances $<2.5 \mathrm{~kb}$, to 0.66 at distances between 400 and $500 \mathrm{~kb}$, with an overall average of 0.85 (Table 1). Even though the LD decay with the increase in distance is clear

Table 1 Summary of SNP pairs, average linkage disequilibrium $\left(r^{2}\right)$, standard deviation (SD), median, persistence of LD phase (PL) between CA and MA genetic groups by genomic distance

\begin{tabular}{|c|c|c|c|c|c|c|c|c|c|c|c|c|c|}
\hline \multirow[t]{2}{*}{ Distance (kb) } & \multicolumn{4}{|c|}{$C A^{1}$} & \multicolumn{4}{|c|}{$M A^{2}$} & \multicolumn{4}{|c|}{ CAN $^{3}$} & \multirow[t]{2}{*}{ PL } \\
\hline & SNP pairs & $r^{2}$ & SD & Median & SNP pairs & $r^{2}$ & SD & Median & SNP pairs & $r^{2}$ & SD & Median & \\
\hline$<2.5$ & 407,763 & 0.40 & 0.38 & 0.27 & 401,469 & 0.33 & 0.33 & 0.21 & 409,164 & 0.38 & 0.36 & 0.26 & 0.96 \\
\hline $2.5-5.0$ & 561,174 & 0.37 & 0.37 & 0.23 & 552,492 & 0.30 & 0.32 & 0.18 & 563,114 & 0.34 & 0.35 & 0.22 & 0.95 \\
\hline $5.0-7.5$ & 531,897 & 0.34 & 0.35 & 0.20 & 523,596 & 0.27 & 0.31 & 0.15 & 533,663 & 0.31 & 0.33 & 0.18 & 0.95 \\
\hline $7.5-10$ & 519,006 & 0.31 & 0.34 & 0.18 & 510,908 & 0.25 & 0.29 & 0.13 & 520,759 & 0.29 & 0.32 & 0.16 & 0.94 \\
\hline $10-20$ & $2,007,682$ & 0.27 & 0.32 & 0.14 & $1,976,524$ & 0.22 & 0.27 & 0.10 & $2,014,438$ & 0.25 & 0.29 & 0.13 & 0.93 \\
\hline $20-30$ & $1,946,916$ & 0.23 & 0.29 & 0.11 & $1,915,942$ & 0.18 & 0.24 & 0.08 & $1,953,735$ & 0.21 & 0.26 & 0.10 & 0.91 \\
\hline $30-40$ & 1,912,997 & 0.20 & 0.26 & 0.09 & $1,882,863$ & 0.16 & 0.22 & 0.07 & $1,919,643$ & 0.18 & 0.24 & 0.08 & 0.90 \\
\hline $40-50$ & $1,893,506$ & 0.18 & 0.25 & 0.08 & $1,863,542$ & 0.14 & 0.20 & 0.06 & $1,900,075$ & 0.16 & 0.22 & 0.07 & 0.88 \\
\hline $50-60$ & $1,878,923$ & 0.16 & 0.23 & 0.07 & $1,848,963$ & 0.13 & 0.19 & 0.05 & $1,885,467$ & 0.15 & 0.21 & 0.06 & 0.87 \\
\hline $60-70$ & $1,866,531$ & 0.15 & 0.22 & 0.06 & $1,836,777$ & 0.11 & 0.18 & 0.05 & $1,873,058$ & 0.13 & 0.20 & 0.06 & 0.86 \\
\hline $70-80$ & $1,857,712$ & 0.14 & 0.21 & 0.06 & $1,828,186$ & 0.11 & 0.17 & 0.04 & $1,864,285$ & 0.13 & 0.19 & 0.05 & 0.85 \\
\hline $80-90$ & $1,852,950$ & 0.13 & 0.20 & 0.06 & $1,823,709$ & 0.10 & 0.16 & 0.04 & $1,859,564$ & 0.12 & 0.18 & 0.05 & 0.84 \\
\hline $90-100$ & $1,848,344$ & 0.13 & 0.19 & 0.05 & $1,819,128$ & 0.09 & 0.15 & 0.04 & $1,855,025$ & 0.11 & 0.17 & 0.05 & 0.83 \\
\hline $100-200$ & $18,280,956$ & 0.10 & 0.17 & 0.04 & $17,988,347$ & 0.07 & 0.12 & 0.03 & $18,345,281$ & 0.09 & 0.14 & 0.04 & 0.78 \\
\hline $200-300$ & $18,079,858$ & 0.08 & 0.14 & 0.03 & $17,787,703$ & 0.06 & 0.09 & 0.03 & $18,143,163$ & 0.07 & 0.11 & 0.03 & 0.72 \\
\hline $300-400$ & $17,964,483$ & 0.07 & 0.13 & 0.03 & $17,674,588$ & 0.05 & 0.08 & 0.02 & $18,027,967$ & 0.06 & 0.10 & 0.02 & 0.68 \\
\hline $400-500$ & $17,862,211$ & 0.07 & 0.12 & 0.03 & $17,575,556$ & 0.05 & 0.07 & 0.02 & $17,926,215$ & 0.06 & 0.09 & 0.02 & 0.66 \\
\hline
\end{tabular}

$1 \mathrm{CA}=$ Canchim animals; $2 \mathrm{MA}=\mathrm{MA}$ genetic group animals; $3 \mathrm{CAN}=\mathrm{CA}$ and $\mathrm{MA}$ animals joined together 
(Figure 1), it is possible to identify some chromosomes (chrs) with lower LD decay among genetic groups, as in chrs 5, 14, and 21 (Figure 2).

The quality control filtering for the haplotype block study was performed using the PLINK v1.07 software [26], which permitted 664,027 SNPs to remain in this study, with an average distance between SNP markers of $3.8 \mathrm{~kb}$, leading to a total autosomal genome size of $2.51 \mathrm{Mb}$. Haplotype blocks formed by only two SNPs were discarded to avoid spurious block formation. A descriptive summary of the haplotype block analysis can also be found in Table 2. From the previous SNPs, 517,393 were clustered into haplotype blocks, which correspond to $78 \%$ of all SNPs, covering $1.57 \mathrm{Mb}$ of the total autosomal genome size (Table 2). Chr 1 showed the highest number of SNPs $(41,830)$ and haplotype blocks $(4,787)$, while chr 25 presented the smallest number of SNPs $(11,671)$ and haplotype blocks $(1,396)$ (Table 2$)$, with an overall average haplotype block length of $20 \mathrm{~kb}$ (Figure 3). Overall, 61\% of chromosome lengths were covered by haplotype blocks, with chrs 23 and 28 showing the smallest coverage (53\%), while chrs 2, 7 and 9 showed the greatest coverage (66\%) (Table 2). Figure 4 displays the haplotype distributions on chrs $7,10,12,15,16,21,23,24,25$, and 29 with some uncommon haplotype distributions (gaps without any haplotype - chrs 10, 12, 23; areas with higher frequencies of larger haplotypes - chrs 7, 12, 16, 24, 29; and uncommon haplotype pattern distributions at the extreme ends - chrs $15,21,25)$.

\section{Discussion}

The choice of using $\mathrm{r}^{2}$ instead of D' for assessing LD measurements was due to the fact that it is less affected by allele frequencies in a finite population size compared to D', which tends to overestimate LD in small samples and low frequency alleles [12,30,31]. According to the literature, mean $\mathrm{r}^{2}$-values above 0.30 can be considered a strong LD and useful for QTL mapping [31], while an mean $\mathrm{r}^{2}$-value of 0.20 is considered enough to achieve an accuracy of 0.85 for genomic breeding value (GBV) estimation [32]. Mean values of $r^{2}=0.30$ and

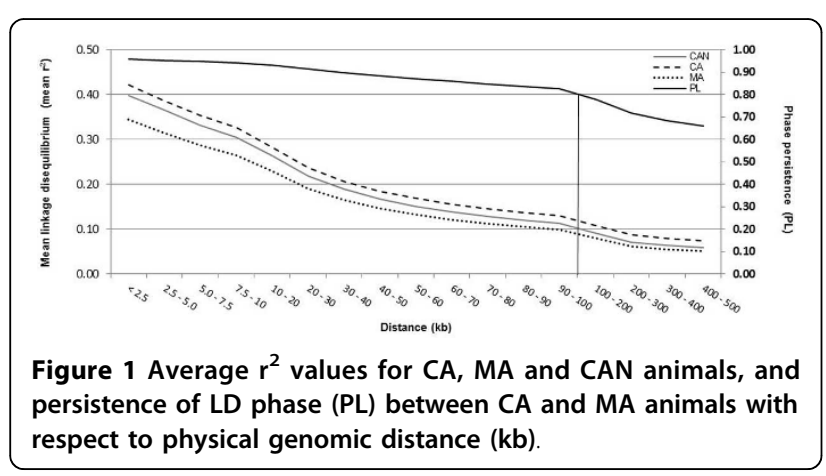

above were found in CA animals extending to the physical genomic distance of $10 \mathrm{~kb}$, being followed by CAN animals at a distance of $7.5 \mathrm{~kb}$, and lastly by MA animals to the physical genomic distance of $5 \mathrm{~kb}$ (Table 1). Considering the great appeal of using SNPs for GBV estimation and the above mentioned threshold of $r^{2}=0.20$, for CA animals GBV can be estimated by using SNP markers at a distance between $30-40 \mathrm{~kb}$, for CAN animals by using SNP markers at distances between 20$30 \mathrm{~kb}$, and for MA animals by using SNP markers at distances between 10-20 kb. Even though making comparisons between LD studies is difficult, as the level of LD varies due to sample size, marker types, density, and population history [33], the results obtained in this study are in agreement with a recent LD study using approximately $700 \mathrm{~kb}$ SNPs in Nellore cattle, which reports levels of $\mathrm{LD}\left(\mathrm{r}^{2}\right)$ higher than 0.30 for SNP markers spanning to a physical genomic distance of $3 \mathrm{~kb}$, and an $\mathrm{r}^{2}$ higher than 0.20 for SNP markers continuing to a physical genomic distance of $20 \mathrm{~kb}$ [13].

Animals from the MA genetic group showed lower levels of LD compared to CA animals (Table 1). This might be explained in part by the crossing system used to obtain MA animals $(\mathrm{CA} \times \mathrm{zebu}=\mathrm{F} 1$, and $\mathrm{F} 1 \times$ Charolais = MA), while most of the CA animals are obtained by $\mathrm{CA} \times \mathrm{CA}$ crosses. Some studies have shown that the average LD decay with the increase in physical genomic distance between loci is more accentuated in crossbred and admixed populations compared to purebred populations $[34,35]$. One of the reasons is that individuals from crossbred populations are less related to each other (further common ancestor), leading to LD haplotypes in crossbred populations being narrower than LD haplotypes in purebreds [35]. In the MA situation, these animals are obtained by initially crossing Canchim with zebu animals, and the progeny are then crossed with Charolais animals. Despite the decrease of LD levels along with the increase in physical genomic distance, the LD behavior also showed variability among chromosomes and chromosomal regions. These variations can be attributed to many factors, such as differences in recombination rates between and within chromosomes, heterozygosity, selection effects, and genetic drift.

The understanding of the persistence of LD phase is essential for effective genomic selection across admixed populations or crossbred animals, as a pair of SNPs can exhibit the same value of $\mathrm{r}^{2}$ between two populations, but in different LD phases [36]. The correlation of the signed $r$ value represents the degree of genetic relationship between populations [37], and between MA and CA animals it was over 0.80 continuing to a genomic distance of $100 \mathrm{~kb}$ between both genetic groups (Table 1), and decreased to a minimum of 0.66 extending to a genomic distance of $500 \mathrm{~kb}$. According to previous 

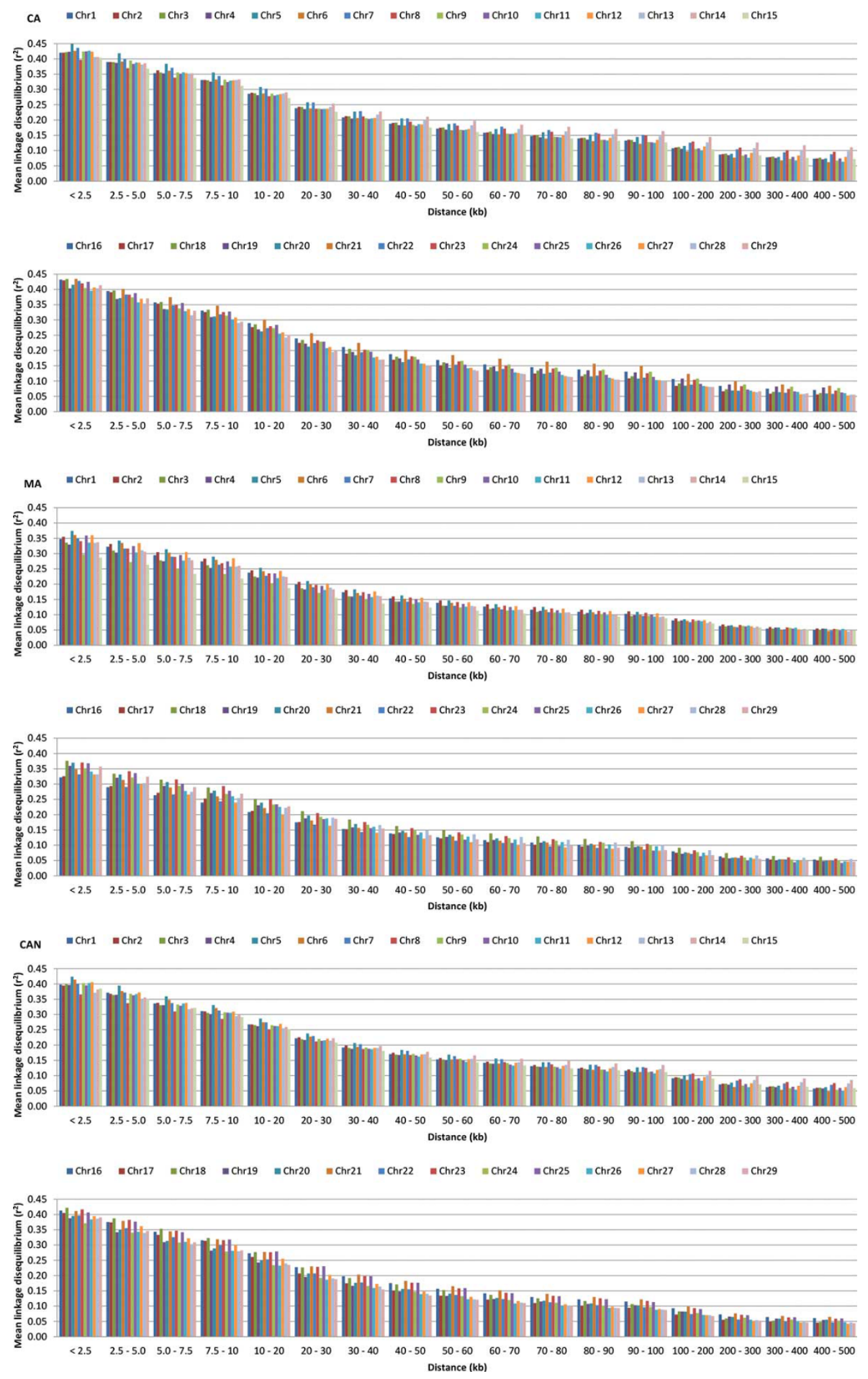

Figure 2 Mean values of linkage disequilibrium $\left(r^{2}\right)$ per chromosome (chr:1-29) according to distance (in kb) between markers for CA, $M A$, and CAN animals.

studies [35,37], high correlation values imply in consistency of LD phase, and considering a threshold of $\mathrm{r}^{2}=$ 0.20 to achieve an accuracy of 0.85 for genomic breeding value estimation [32], the persistence of LD phase between MA and CA animals stayed over 0.91 until reaching a genomic distance of $30 \mathrm{~kb}$, meaning that one population can be used to predict the performance of the other (e.g. MA animals) [12], which allows for considering both 
Table 2 Haplotype block summary per chromosome (chr)

\begin{tabular}{|c|c|c|c|c|c|c|c|c|}
\hline $\mathrm{Chr}$ & $\begin{array}{l}\text { Number of } \\
\text { SNPs }\end{array}$ & $\begin{array}{l}\text { Chr length } \\
(\mathrm{Mb})\end{array}$ & $\begin{array}{c}\text { Average SNPs distance } \\
(\mathrm{kb})\end{array}$ & $\begin{array}{c}\text { Number of } \\
\text { blocks }\end{array}$ & $\begin{array}{c}\text { Block } \\
\text { coverage } \\
\text { length }(\mathrm{Mb})\end{array}$ & $\begin{array}{c}\% \text { Chr block } \\
\text { coverage }\end{array}$ & $\begin{array}{l}\text { SNPs in } \\
\text { blocks }\end{array}$ & $\begin{array}{l}\text { \% SNPs } \\
\text { in } \\
\text { blocks }\end{array}$ \\
\hline 1 & 41,830 & 158,306 & 3.78 & 4,787 & $103,419.90$ & 65 & 33,411 & 80 \\
\hline 2 & 36,178 & 136,763 & 3.78 & 4,118 & $90,048.32$ & 66 & 28,981 & 80 \\
\hline 3 & 32,061 & 121,405 & 3.79 & 3,653 & $79,147.48$ & 65 & 25,442 & 79 \\
\hline 4 & 31,800 & 120,635 & 3.79 & 3,677 & $76,877.07$ & 64 & 25,018 & 79 \\
\hline 5 & 31,160 & 121,182 & 3.89 & 3,446 & $79,131.14$ & 65 & 25,222 & 81 \\
\hline 6 & 32,480 & 119,423 & 3.68 & 3,764 & $76,983.56$ & 64 & 25,998 & 80 \\
\hline 7 & 29,879 & 112,595 & 3.77 & 3,310 & $74,287.94$ & 66 & 23,993 & 80 \\
\hline 8 & 29,907 & 113,346 & 3.79 & 3,414 & $72,761.84$ & 64 & 23,790 & 80 \\
\hline 9 & 28,552 & 105,667 & 3.70 & 3,275 & $69,607.56$ & 66 & 22,817 & 80 \\
\hline 10 & 27,824 & 104,283 & 3.75 & 3,211 & $64,087.69$ & 61 & 21,370 & 77 \\
\hline 11 & 28,788 & 107,269 & 3.73 & 3,252 & $68,632.31$ & 64 & 22,857 & 79 \\
\hline 12 & 23,562 & 91,125 & 3.87 & 2,665 & $55,775.42$ & 61 & 18,327 & 78 \\
\hline 13 & 20,886 & 84,207 & 4.03 & 2,461 & $52,981.54$ & 63 & 16,071 & 77 \\
\hline 14 & 22,235 & 84,035 & 3.78 & 2,596 & $54,099.85$ & 64 & 17,579 & 79 \\
\hline 15 & 22,019 & 85,229 & 3.87 & 2,639 & $52,643.91$ & 62 & 17,107 & 78 \\
\hline 16 & 22,021 & 81,685 & 3.71 & 2,495 & $51,656.07$ & 63 & 17,177 & 78 \\
\hline 17 & 20,144 & 75,146 & 3.73 & 2,377 & $45,306.63$ & 60 & 15,517 & 77 \\
\hline 18 & 17,611 & 65,913 & 3.74 & 2,032 & $39,490.48$ & 60 & 13,492 & 77 \\
\hline 19 & 17,032 & 63,964 & 3.76 & 1,982 & $37,624.33$ & 59 & 12,606 & 74 \\
\hline 20 & 19,407 & 71,950 & 3.71 & 2,324 & $43,679.74$ & 61 & 15,038 & 77 \\
\hline 21 & 19,101 & 71,568 & 3.75 & 2,205 & $46,122.94$ & 64 & 14,919 & 78 \\
\hline 22 & 16,610 & 61,279 & 3.69 & 1,893 & $36,982.78$ & 60 & 12,655 & 76 \\
\hline 23 & 13,695 & 52,459 & 3.83 & 1,660 & $27,629.29$ & 53 & 9,482 & 69 \\
\hline 24 & 16,983 & 62,542 & 3.68 & 1,948 & $38,866.11$ & 62 & 13,065 & 77 \\
\hline 25 & 11,671 & 42,823 & 3.67 & 1,396 & $23,924.44$ & 56 & 8,522 & 73 \\
\hline 26 & 13,820 & 51,642 & 3.74 & 1,657 & $30,037.78$ & 58 & 10,402 & 75 \\
\hline 27 & 11,822 & 45,400 & 3.84 & 1,447 & $24,658.49$ & 54 & 8,573 & 73 \\
\hline 28 & 11,872 & 46,243 & 3.90 & 1,411 & $24,333.07$ & 53 & 8,406 & 71 \\
\hline 29 & 13,077 & 51,180 & 3.91 & 1,578 & $28,700.01$ & 56 & 9,556 & 73 \\
\hline Total & 664,027 & $2,509,262$ & $3.78 \pm 0.08$ & 76,673 & $1,569,498$ & $61 \pm 4$ & 517,393 & $77 \pm 3$ \\
\hline
\end{tabular}

genetic groups (CA and MA animals) together as one breed (CAN animals) for future studies and for genetic evaluation purposes.

There are many published studies on LD and haplotype block properties for cattle, which vary in many aspects (breed of interest, marker types, marker density, and chromosome regions), yielding average haplotype block sizes from a few $\mathrm{kb}$ in length $(5.7 \mathrm{~kb}$ considering 2 or more SNPs [9], $26.2 \mathrm{~kb}$ considering 4 or more SNPs [8]) to hundreds of $\mathrm{kb}$ in length (700 kb [6]), and covering from $2.18 \%$ to $4.67 \%[4,10]$ of the detected genome. However, these studies used smaller marker

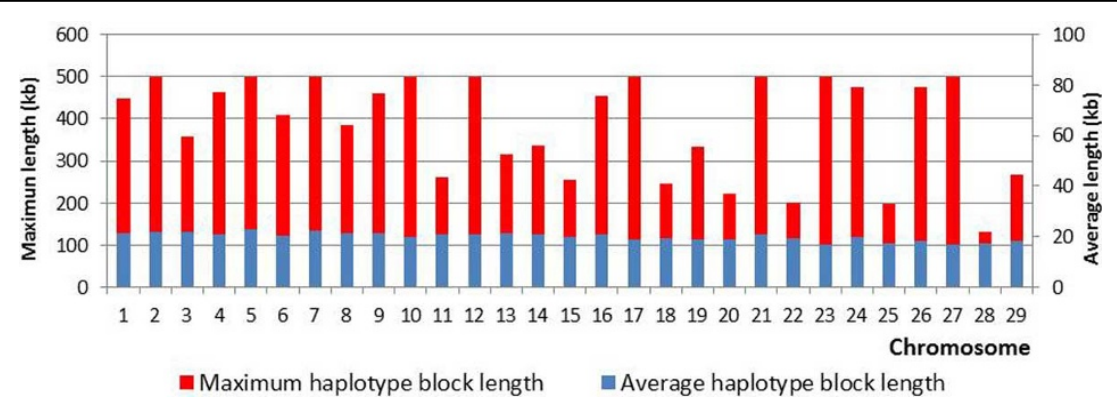

Figure 3 Maximum and average haplotype block length per chromosome 

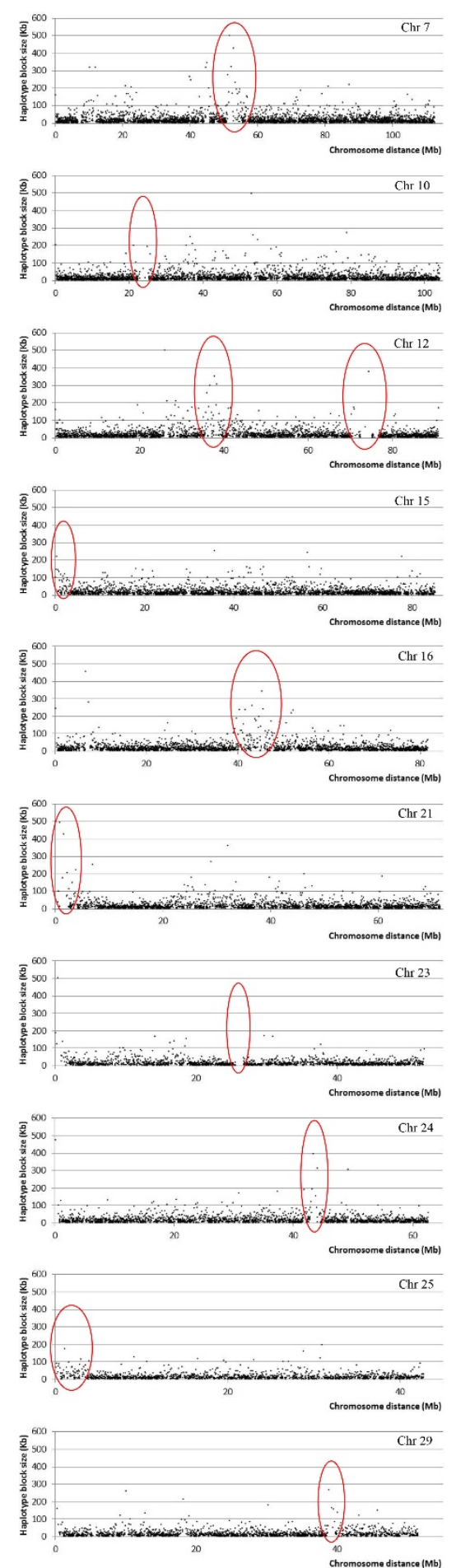

Figure 4 Haplotype block distributions for chromosomes (chrs) $7,10,12,15,16,21,23,24,25$ and 29 (red ellipses for highlighted area of uncommon haplotype block distribution: gaps without any haplotype - chrs10, 12, 23; areas with higher frequencies of larger haplotypes - chrs 7, 12, 16, 24, 29; and uncommon haplotype pattern distributions at the extreme ends - chrs 15, 21, 25). densities, with an average distance of $62 \mathrm{~kb}$ between adjacent markers [10]. Another study, which considered only high-density markers in specific areas of the bovine genome (approximate distances of $5 \mathrm{~kb}$ between adjacent markers), reported an average block size of $10.3 \mathrm{~kb}$ across many breeds, an average of 3.8 SNPs per block, and a total of $34 \%$ of the high-density areas covered by haplotype blocks [9]. These values are still smaller than the ones reported in this study for percentage of covered genome (61\%), average number of SNPs per block (6.64 SNPs), and a total of 78\% SNPs in haplotype blocks, corroborating the assumption that as the marker density increases, the more haplotype blocks of smaller sizes will be identified. On the other hand, this is not supported in total by a study in German Holstein cattle, which did not report relevant variation on haplotype block number with the increase of marker density, but an increase in block coverage percentage [10].

There are many aspects reported in the literature involved in LD shaping, which in turn affects the haplotype block structure, such as meiotic recombination, natural and artificial selection, population bottle necks, genetic drift, and admixture [29,38-42]. However, most of these studies were carried out in humans [39-42], which, among other differences, are not affected by artificial selection and have a higher effective population size than cattle [43]. All these factors play important roles in the haplotype block structure which could be the cause of some of the uncommon haplotype distributions found in Figure 4.

\section{Conclusions}

This study describes the first high-density linkage disequilibrium map and haplotype block structure for a composite beef cattle population. Considering an $r^{2} \geq$ 0.20 as being useful for genomic breeding value estimations, the results demonstrate that the high density SNP panel used here can be implemented for genomic selection of Canchim beef cattle. The persistence of LD phase between CA and MA animals was consistent, which supports the decision of considering both genetic groups together in future studies and in genetic evaluation programs. Further studies on factors affecting the uncommon haplotype block distribution still need to be carried out in order to better understand the way these factors are shaping the LD and haplotype blocks.

\section{Availability of supporting data}

The genomic data and further supporting data are available upon request from Dr. Luciana Correia de Almeida Regitano (Embrapa Southeast Livestock. Address: Rodovia Washington Luiz, km 234, São Carlos, São Paulo, 
13560-970, Brazil; e-mail: luciana.regitano@embrapa.br; telephone: +55 16 34115600).

\section{Competing interests}

The authors declare that they have no competing interests.

\section{Authors' contributions}

FBM, MEB: contributed equally for the development of this research with data analysis, interpretation, figure compositions, manuscript writing and revision. MAM: data analysis, manuscript discussion and revision. DAG: data analysis, interpretation of results, manuscript revision. RHH: data analysis, manuscript discussion and revision. RW: data analysis, interpretation. AOL: data analysis, interpretation of results, manuscript revision. MS: provided the SNPPLD software, interpretation. SLCM: experimental design, manuscript revision. FSS: results interpretation and discussion. MVGBS: experimental design, manuscript revision. SCMN: experimental design, DNA handling, manuscript revision. MMA: experimental design. DPM: data interpretation LCAR: experimental design, interpretation, and manuscript revision.

\section{Acknowledgements}

The authors would like to acknowledge all technicians involved in this study for providing excellent assistance, the Embrapa Bioinformatics Multi-Users Laboratory for its facility and human resources, and also to the Canchim Breed Association for providing DNA material. We thank Dr. David Z. Mokry for English revisions and corrections. This article was funded by grants from CAPES/PNPD n 02663/09-0 (Coordination for Enhancement of Higher Education Personnel), and Embrapa (Brazilian Agricultural Research Corporation). The funding agencies had no role in study design, data collection and analysis, interpretation, decision to publish, or preparation of the manuscript.

Marcos Vinicius Gualberto Barbosa da Silva, Maurício Mello de Alencar, Luciana Correia de Almeida Regitano, and Marcos Eli Buzanskas (142053/ 2010-4) are CNPq fellows. Fabiana Barichello Mokry, Andressa Oliveira de Lima, and Marcos Eli Buzanskas (5285-11-9) are CAPES fellows. This article has been published as part of BMC Genomics Volume 15 Supplement 7, 2014: Proceedings of the 9th International Conference of the Brazilian Association for Bioinformatics and Computational Biology (XMeeting 2013). The full contents of the supplement are available online at http://www.biomedcentral.com/bmcgenomics/supplements/15/S7.

\section{Authors' details}

'Department of Genetics and Evolution, Federal University of São Carlos, Rodovia Washington Luiz, km 235, PO BOX 676, 13565-905, São Carlos, Brazil. 2 Departamento de Ciências Exatas, UNESP - Univ Estadual Paulista, Faculdade de Ciências Agrárias e Veterinárias, Jaboticabal, SP, 14884-900, Brazil. ${ }^{3}$ Embrapa Southeast Livestock, Rodovia Washington Luiz, km 234, PO BOX 339, 13560-970, São Carlos, Brazil. ${ }^{4}$ Centre for Genetic Improvement of Livestock, University of Guelph, 50 Stone Road East N1G 2W1, Guelph, Ontario, Canada. ${ }^{5}$ Embrapa Agricultural Informatics, Avenida André Tosello, 209, PO BOX 6041, 13083-886, Campinas, Brazil. 'Department of Animal Science, Federal University of Lavras, PO BOX 3037, 37200-00, Lavras, Brazil. ${ }^{7}$ Embrapa Dairy Cattle, Rua Eugênio do Nascimento, 610, 36038-330, Juiz de Fora, Brazil.

Published: 27 October 2014

\section{References}

1. De La Vega FM, Dailey D, Ziegle J, Williams J, Madden D, Gilbert DA: New generation pharmacogenomic tools: a SNP linkage disequilibrium Map, validated SNP assay resource, and high-throughput instrumentation system for large-scale genetic studies. Biotechniques 2002, , 48-50: 52-54.

2. Hedrick PW: Genetics Of Populations. Jones and Bartlett Publishers; 2005, Biological Science (Jones and Bartlett) Series.

3. Farnir F, Coppieters W, Arranz J, Berzi P, Cambisano N, Grisart B, Karim L, Marcq F, Moreau L, Mni M, Nezer C, Simon P, Vanmanshoven P, Wagenaar D, Georges M: Extensive Genome-wide Linkage Disequilibrium in Cattle. Genome Res 2000, 10:220-227.

4. Khatkar MS, Zenger KR, Hobbs M, Hawken RJ, Cavanagh JAL, Barris W, McClintock AE, McClintock S, Thomson PC, Tier B, Nicholas FW,
Raadsma HW: A primary assembly of a bovine haplotype block map based on a 15,036-single-nucleotide polymorphism panel genotyped in holstein-friesian cattle. Genetics 2007, 176:763-72.

5. Odani M, Narita A, Watanabe T, Yokouchi K, Sugimoto Y, Fujita T, Oguni T, Matsumoto M, Sasaki Y: Genome-wide linkage disequilibrium in two Japanese beef cattle breeds. Anim Genet 2006, 37:139-44.

6. Gautier M, Faraut T, Moazami-Goudarzi K, Navratil V, Foglio M, Grohs C, Boland A, Garnier J-G, Boichard D, Lathrop GM, Gut IG, Eggen A: Genetic and haplotypic structure in 14 European and African cattle breeds. Genetics 2007, 177:1059-70.

7. McKay SD, Schnabel RD, Murdoch BM, Matukumalli LK, Aerts J, Coppieters W, Crews D, Dias Neto E, Gill CA, Gao C, Mannen H, Stothard P, Wang Z, Van Tassell CP, Williams JL, Taylor JF, Moore SS: Whole genome linkage disequilibrium maps in cattle. BMC Genet 2007, 8:74.

8. Kim E-S, Kirkpatrick BW: Linkage disequilibrium in the North American Holstein population. Anim Genet 2009, 40:279-88.

9. Villa-Angulo R, Matukumalli LK, Gill CA, Choi J, Van Tassell CP, Grefenstette JJ: High-resolution haplotype block structure in the cattle genome. BMC Genet 2009, 10:19.

10. Qanbari S, Pimentel ECG, Tetens J, Thaller G, Lichtner P, Sharifi AR, Simianer $\mathrm{H}$ : The pattern of linkage disequilibrium in German Holstein cattle. Anim Genet 2010, 41:346-56.

11. Flury C, Tapio M, Sonstegard T, Drögemüller $C$, Leeb T, Simianer $H$, Hanotte O, Rieder S: Effective population size of an indigenous Swiss cattle breed estimated from linkage disequilibrium. J Anim Breed Genet 2010, 127:339-47.

12. Lu D, Sargolzaei M, Kelly M, Li C, Vander Voort G, Wang Z, Plastow G, Moore S, Miller SP: Linkage disequilibrium in Angus, Charolais, and Crossbred beef cattle. Front Genet 2012, 3:152, August.

13. Espigolan R, Baldi F, Boligon AA, Souza FR, Gordo DG, Tonussi RL, Cardoso DF, Oliveira HN, Tonhati H, Sargolzaei M, Schenkel FS, Carvalheiro R, Ferro JA, Albuquerque LG: Study of whole genome linkage disequilibrium in Nellore cattle. BMC Genomics 2013, 14:305.

14. Johnson GC, Esposito L, Barratt BJ, Smith AN, Heward J, Di Genova G, Ueda H, Cordell HJ, Eaves IA, Dudbridge F, Twells RC, Payne F, Hughes W, Nutland S, Stevens H, Carr P, Tuomilehto-Wolf E, Tuomilehto J, Gough SC, Clayton DG, Todd JA: Haplotype tagging for the identification of common disease genes. Nat Genet 2001, 29:233-7.

15. Sabeti PC, Reich DE, Higgins JM, Levine HZP, Richter DJ, Schaffner SF, Gabriel SB, Platko J V, Patterson NJ, McDonald GJ, Ackerman HC, Campbell SJ, Altshuler D, Cooper R, Kwiatkowski D, Ward R, Lander ES: Detecting recent positive selection in the human genome from haplotype structure. Nature 2002, 419:832-7.

16. Vianna AT: Formação Do Gado Canchim Pelo Cruzamento Charoles-Zebu. Ministério da Agricultura 1960, 48, SIA. Estudos T\{é\}cnicos.

17. Alencar MM: Bovino - Raça Canchim: Origem E Desenvolvimento. EMBRAPA-UEPAE de São Carlos 1986.

18. Associação Brasileira de Criadores de Canchim: Raça Canchim: $\mathrm{O}$ precoce brasileiro. Merc da Carne 2008, 28-31.

19. Associação Brasileira de Inseminação Artificial: Índex Asbia: Importação, Exportação E Comercialização de Sêmen. 2012, 19.

20. Zimin A V, Delcher AL, Florea L, Kelley DR, Schatz MC, Puiu D, Hanrahan F, Pertea G, Van Tassell CP, Sonstegard TS, Marçais G, Roberts M, Subramanian P, Yorke JA, Salzberg SL: A whole-genome assembly of the domestic cow, Bos taurus. Genome Biol 2009, 10:R42.

21. Goddard KA, Hopkins PJ, Hall JM, Witte JS: Linkage disequilibrium and allele-frequency distributions for 114 single-nucleotide polymorphisms in five populations. Am J Hum Genet 2000, 66:216-34.

22. Sargolzaei M, Schenkel F, VanRaden P: gebv: Genomic breeding value estimator for livestock. Tech Rep to Dairy Cattle Breed Genet Comm 2009, 1-7, University of Guelph.

23. Hill W, Robertson A: Linkage disequilibrium in finite populations. Theor Appl Genet 1968, 38:226-231.

24. Badke YM, Bates RO, Ernst CW, Schwab C, Steibel JP: Estimation of linkage disequilibrium in four US pig breeds. BMC Genomics 2012, 13:24.

25. The International HapMap Consortium: A haplotype map of the human genome. Nature 2005, 437:1299-320.

26. Purcell S, Neale B, Todd-Brown K, Thomas L, Ferreira MAR, Bender D, Maller J, Sklar P, de Bakker PIW, Daly MJ, Sham PC: PLINK: a tool set for whole-genome association and population-based linkage analyses. Am J Hum Genet 2007, 81:559-75. 
27. Browning SR, Browning BL: Rapid and accurate haplotype phasing and missing-data inference for whole-genome association studies by use of localized haplotype clustering. Am J Hum Genet 2007, 81:1084-97.

28. Barrett JC, Fry B, Maller J, Daly MJ: Haploview: analysis and visualization of LD and haplotype maps. Bioinformatics 2005, 21:263-5.

29. Gabriel SB, Schaffner SF, Nguyen H, Moore JM, Roy J, Blumenstiel B, Higgins J, DeFelice M, Lochner A, Faggart M, Liu-Cordero SN, Rotimi C, Adeyemo A, Cooper R, Ward R, Lander ES, Daly MJ, Altshuler D: The structure of haplotype blocks in the human genome. Science 2002, 296:2225-9.

30. Hedrick PW: Gametic disequilibrium measures: proceed with caution. Genetics 1987, 117:331-41.

31. Ardlie $K G$, Kruglyak $L$, Seielstad M: Patterns of linkage disequilibrium in the human genome. Nat Rev Genet 2002, 3:299-309.

32. Meuwissen TH, Hayes BJ, Goddard ME: Prediction of total genetic value using genome-wide dense marker maps. Genetics 2001, 157:1819-1829.

33. Pritchard JK, Przeworski M: Linkage disequilibrium in humans: models and data. Am J Hum Genet 2001, 69:1-14

34. Shifman S: Linkage disequilibrium patterns of the human genome across populations. Hum Mol Genet 2003, 12:771-776.

35. Toosi A, Fernando RL, Dekkers JCM: Genomic selection in admixed and crossbred populations. J Anim Sci 2010, 88:32-46.

36. Goddard ME, Hayes BJ, McPartlan H, Chamberlain AJ: Can the same genetic markers be used in multiple breeds? Proc 8th World Congr Genet Appl to Livest Prod Belo Horizonte, Brazil 2006 2006, 16-22.

37. De Roos APW, Hayes BJ, Spelman RJ, Goddard ME: Linkage disequilibrium and persistence of phase in Holstein-Friesian, Jersey and Angus cattle. Genetics 2008, 179:1503-12.

38. Daly MJ, Rioux JD, Schaffner SF, Hudson TJ, Lander ES: High-resolution haplotype structure in the human genome. Nat Genet 2001, 29:229-32.

39. Zhang K, Akey JM, Wang N, Xiong M, Chakraborty R, Jin L: Randomly distributed crossovers may generate block-like patterns of linkage disequilibrium: an act of genetic drift. Hum Genet 2003, 113:51-9.

40. Greenwood TA, Rana BK, Schork NJ: Human haplotype block sizes are negatively correlated with recombination rates. Genome Res 2004 14:1358-61.

41. Greenawalt DM, Cui X, Wu Y, Lin Y, Wang H-Y, Luo M, Tereshchenko I V, Hu G, Li JY, Chu Y, Azaro MA, Decoste CJ, Chimge N-O, Gao R, Shen L, Shih WJ, Lange K, Li H: Strong correlation between meiotic crossovers and haplotype structure in a $2.5-\mathrm{Mb}$ region on the long arm of chromosome 21. Genome Res 2006, 16:208-14.

42. Phillips MS, Lawrence $R$, Sachidanandam R, Morris AP, Balding DJ, Donaldson MA, Studebaker JF, Ankener WM, Alfisi S V, Kuo F-S, Camisa AL, Pazorov V, Scott KE, Carey BJ, Faith J, Katari G, Bhatti HA, Cyr JM, Derohannessian V, Elosua C, Forman AM, Grecco NM, Hock CR, Kuebler JM, Lathrop JA, Mockler MA, Nachtman EP, Restine SL, Varde SA, Hozza MJ, et al: Chromosome-wide distribution of haplotype blocks and the role of recombination hot spots. Nat Genet 2003, 33:382-7.

43. Hayes BJ, Visscher PM, McPartlan HC, Goddard ME: Novel multilocus measure of linkage disequilibrium to estimate past effective population size. Genome Res 2003, 13:635-43.

doi:10.1186/1471-2164-15-S7-S6

Cite this article as: Mokry et al:: Linkage disequilibrium and haplotype block structure in a composite beef cattle breed. BMC Genomics 2014 15(Suppl 7):S6

\section{Submit your next manuscript to BioMed Central and take full advantage of:}

- Convenient online submission

- Thorough peer review

- No space constraints or color figure charges

- Immediate publication on acceptance

- Inclusion in PubMed, CAS, Scopus and Google Scholar

- Research which is freely available for redistribution

Submit your manuscript at www.biomedcentral.com/submit
Biomed Central 